\title{
Behavioral responses of juvenile leatherbacks Dermochelys coriacea to lights used in the longline fishery
}

\author{
Jodie M. Gless, Michael Salmon*, Jeanette Wyneken \\ Department of Biological Sciences, Florida Atlantic University, Box 3091, 777 Glades Road, Boca Raton, \\ Florida 33431 - 0991, USA
}

\begin{abstract}
Sea turtles are injured and sometimes killed because of interactions with pelagic longlines, such as hook ingestion, entanglement in the lines, and forced submergence. Stimuli from bait, gear and lights (often used at night on swordfish lines) might attract sea turtles. Previous experiments with loggerheads Caretta caretta demonstrated that the turtles were attracted to the lights, but no comparable studies have been done with other species. Our goal in this study was to determine whether juvenile leatherbacks Dermochelys coriacea, reared in the laboratory for 5 to $42 \mathrm{~d}$ postemergence, responded to the lights in the same way as loggerheads. Each leatherback was presented once in varying order with 3 different colored light stimuli from either chemical lightsticks $(\mathrm{n}=$ 16 turtles) or battery powered LEDs ( $\mathrm{n}=16$ turtles) commonly used in the fishery. Most leatherbacks, in contrast to loggerheads, either failed to orient or oriented at an angle away from the lights. These results imply that the capture of leatherbacks on longlines might occur for other reasons (by accident, through attraction to bait odor or to concentrations of natural prey located near the lines). Alternatively, older turtles might show responses that differ from those of juvenile turtles. We review previous studies based upon logbook data and conclude that because of confounding factors, there is no convincing evidence that marine turtles are attracted to the longlines by lights. We recommend that better-designed field experiments be carried out to determine whether fishery lights have an effect on marine turtle capture rates.
\end{abstract}

KEY WORDS: Longlines · Bycatch · Sea turtle $\cdot$ Dermochelys coriacea $\cdot$ Caretta caretta $\cdot$ Fishery lights · Orientation

Resale or republication not permitted without written consent of the publisher

\section{INTRODUCTION}

Both Pacific leatherbacks Dermochelys coriacea (Sutanto-Suwelo et al. 1994, Chan \& Liew 1996, Spotila et al. 2000) and Pacific loggerheads Caretta caretta (reviewed by Kamezaki et al. 2003, Limpus \& Limpus 2003) populations are in a rapid and precipitous decline in terms of the number of nesting females, and are considered critically endangered or endangered species (IUCN 1994). In the Atlantic some leatherback beaches are experiencing stable or increasing numbers of nesting females (Stewart 2007) while others are in decline (Troëng et al. 2007, TEWG 2007). Although some loggerhead subpopulations have been increas- ing (Marcovaldi \& Chaloupka 2007), the largest (Florida) subpopulation has recently been declining after years of increase (Meylan et al. 2006, NMFS and USFWS 2007).

Among the threats are direct turtle and egg harvest, egg predation by non-native animals, nesting beach habitat degradation or loss, and pollution (see reviews by Hoyle 1994, Lutcavage et al. 1997, Bugoni et al. 2001, Parris et al. 2002). Many marine turtles are also incidentally captured and injured though fisheries interactions, including longlines (Lewison \& Crowder 2007). Recent estimates are that in the year 2000 alone, longlines incidentally captured 200000 loggerheads and 50000 leatherbacks, and that thousands of these 
turtles probably died of injuries resulting from their capture (Lewison et al. 2004a). Many of these turtles are leatherbacks approaching sexual maturity or leatherback adults with high reproductive value (Lewison \& Crowder 2007), the age classes most important for the future recovery of populations. Unless these fishery threats are reduced or eliminated, marine turtle populations, especially in the Pacific, are threatened with extinction (Lewison et al. 2004b).

This problem has prompted the support of studies on gear modification and changes in fishing practices, as well as their testing in both the Atlantic (Bolten et al. 2002, Bolten \& Bjorndal 2003, 2004, 2005) and Pacific (Boggs 2004) ocean basins. Results to date indicate that changes in baits, hook configuration, set duration, depth and location, and set timing relative to the photocycle substantially reduce, but do not eliminate, turtle bycatch rates (Bolten \& Bjorndal 2003, Watson et al. 2004, 2005, Gilman et al. 2007) .

Given the critically depleted state of these marine turtle populations, especially in the Pacific, capture rates by the fishery must be further reduced or, preferably, eliminated altogether. In response to this challenge, efforts have recently focused on a new approach: to determine how marine turtles and the target fish species differ in their ability to detect and respond behaviorally to 'longline-generated' stimuli that may attract them to the hooks (Swimmer \& Brill 2006). If differences can be defined, then modifications might be introduced that enable the capture of the target fishes, but not the turtles. Experiments have focused upon the chemical (stimuli from baits) and visual (stimuli from the lights placed near the baits) senses (Southwood et al. 2006, Fritsches \& Warrant 2006, Johnsen 2006, Wang et al. 2007). While some promising differences, especially in visual physiology, have been discovered, field studies have not yet been initiated to determine whether any of them can be successfully exploited.

Recent laboratory studies (Lohmann et al. 2006, Wang et al. 2007) have established that juvenile loggerheads are attracted to the lights used on longlines. Our purpose in the present study was to determine whether juvenile leatherbacks, whose responses to these lights are unknown, behave similarly. This information is required because both species are often captured on longlines (Watson et al. 2005) and therefore modifications to lighting gear must be based upon a firm understanding of how both species react to these stimuli.

\section{MATERIALS AND METHODS}

Turtles. Hatchlings were obtained in July and August, 2006 and 2007, at locations between Broward $\left(26^{\circ} \mathrm{N}, 80^{\circ} \mathrm{W}\right)$ and Brevard $\left(28^{\circ} \mathrm{N}, 80^{\circ} \mathrm{W}\right)$ counties, Florida, USA. The turtles were collected at night as they emerged from nests, or in the early morning from the inside of predator exclusion cages that covered the nests at some beaches. Turtles were transported in covered Styrofoam ${ }^{\mathrm{TM}}$ boxes to the Florida Atlantic University Marine Laboratory at Boca Raton $\left(26.24^{\circ} \mathrm{N}\right.$, $80.03^{\circ} \mathrm{W}$ ) where they were reared, and where experimental studies were carried out. After testing was completed, all the turtles were released 5 to $15 \mathrm{~km}$ offshore in the Gulf Stream.

On the day of capture and at $1 \mathrm{wk}$ intervals thereafter, each turtle's standard straight line carapace length (SCL), carapace width and body depth was measured using vernier calipers (accurate to the nearest $0.1 \mathrm{~mm}$ ) to assess normal growth and condition. Mass was measured using an electronic scale (accurate to the nearest $0.01 \mathrm{~g}$ ). Testing was conducted after the turtles began feeding, between 5 and $42 \mathrm{~d}$ post-emergence. They ranged in size between 55.0 and $90.3 \mathrm{~mm}$ SCL and in mass between 38.7 and $125.0 \mathrm{~g}$.

Turtles were reared in large tanks and tethered (using 20 to $30 \mathrm{~cm}$ of monofilament line attached to the carapace by a Velcro ${ }^{\mathrm{TM}}$ patch held in place with surgical cyanoacrylate glue; Jones et al. 2000) so that they could swim in any direction but could not contact the tank walls or bottom. Tethering is required because leatherbacks do not recognize barriers, and contact with hard surfaces can lead to skin abrasion and infection (Spoczynska 1970, Witham 1977). Leatherbacks tethered for several weeks during rearing show clear orientation responses to either visual or chemical stimuli (Constantino \& Salmon 2003).

Each rearing tank received filtered, sterilized and chilled $\left(22 \pm 2^{\circ} \mathrm{C}\right)$ seawater changed twice daily. Turtles were fed to satiation 3 times daily on a diet of minced squid or fish embedded in gelatin, with the addition of reptile vitamins and minerals plus carbohydrate. Only turtles that were in excellent condition and eating normally were used for experiments. A 12:12 h light-dark photocycle was maintained during rearing.

There was only sufficient space to rear 24 turtles each year. For this reason, 24 turtles were tested in 2006, and an additional 8 turtles were tested in 2007.

Measurement of orientation. Experiments were done at night inside each of 2 flat-black colored circular polyethylene tanks (capacity $300 \mathrm{l}$ ) filled to a depth of $45 \mathrm{~cm}$ with filtered sterilized and chilled seawater (Fig. 1). Both tanks were covered with a light-tight lid while tests were in progress. The following morning each tank was drained, washed with disinfectant and refilled with new filtered seawater in preparation for additional experiments. Water temperatures inside the test tanks did not differ from those inside the holding tanks. 


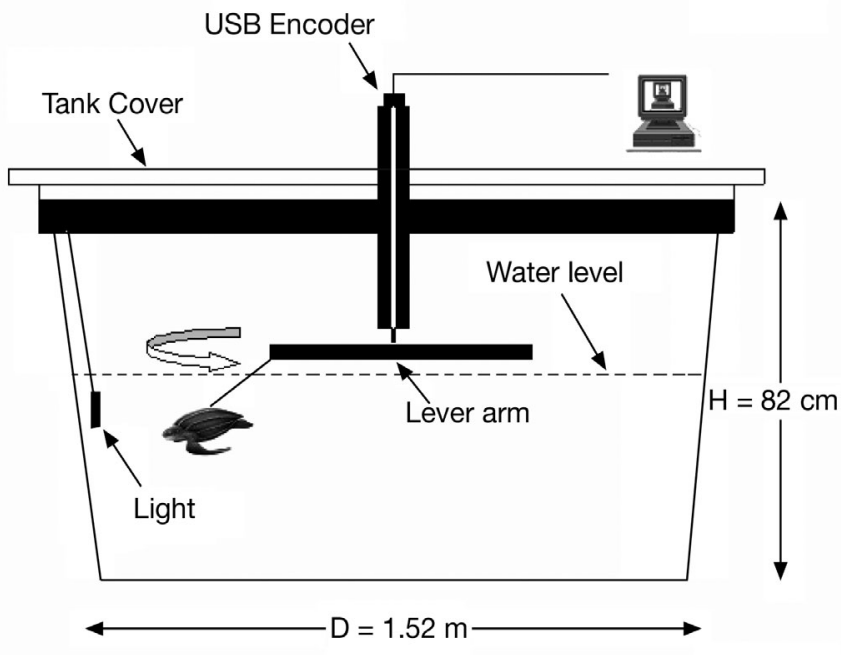

Fig. 1. Diagram of test tank showing dimensions and equipment used to record orientation. H: height, D: diameter

Because leatherbacks take several hours to recover from handling, turtles were transferred from their rearing to the test tanks in the afternoon and then left undisturbed until evening. The tank cover was closed at dusk. Each transferred turtle was tethered as previously described by a short length of monofilament line tied to a horizontally rotating lever arm positioned above the center of the test tank (Fig. 1). As the turtle changed its swimming direction it rotated the lever arm behind it, so that the arm's position reflected the turtle's swimming direction (Wang et al. 2007). The arm (a lightweight wood dowel) was attached to a USB encoder and an analog-to-digital converter that sent the data (a swimming angle between 0 and $359^{\circ}$ ) to a computer at $10 \mathrm{~s}$ intervals. A software program ('Arena Tracker $^{{ }^{\odot}}$, W. Irwin, University of North Carolina) stored each swimming angle as a direction relative to the light source $\left(0^{\circ}\right)$ throughout a 10 min test period. At the end of the test, the program converted the 60 swimming directions to a mean angle of orientation and r-vector (measure of dispersion).

Stimuli. The light stimuli were green, blue, and yellow chemical lightsticks (Northern Light Products) and green, blue, and orange battery powered LED lights (Electralumes ${ }^{\circledR}$, Lindgren-Pitman; see Fig. 2), suspended vertically in the tanks just below water level (Fig. 1). All are used in the US fishery. The same stimulus colors were used in tests with loggerheads (Wang et al. 2007). Spectra and irradiance of each light were measured at a distance of $\sim 5 \mathrm{~cm}$ (the closest distance that a swimming turtle could approach the lights) using a spectrometer (Ocean Optics USB 2000, fiber diameter $3.0 \mathrm{~mm}$ ) and a radiometer (Model 521A, uniform sensitivity between 400 and $700 \mathrm{~nm}$; UDT Instruments).
Test protocol. Each evening, the light source was rotated $90^{\circ}$ to the right of its location during the previous evening, and the lever arm direction when pointed at the light was set to $0^{\circ}$. All studies began at 23:00 h, and concluded after each turtle had been exposed to all 3 of the lightstick or LED colors, plus its control (a lightstick that had not been activated; an LED disconnected from its battery). Presentation order (of the light colors and the control treatment) was varied for each turtle.

Testing began after the cover was opened and a light was suspended inside the tank. The tank cover was then closed and the turtle was given 3 min to acclimatize to the stimulus before its orientation was recorded for the next $10 \mathrm{~min}$ (Fig. 2). At the conclusion of the test the tank cover was opened, the stimulus was removed, and the cover was closed. After $5 \mathrm{~min}$, a new stimulus was introduced. This sequence was repeated until each turtle had been exposed to each of the 3 light colors and a control treatment. The turtle was then returned to its holding tank.

Statistics. The mean angles for the turtles exposed to LEDs and lightsticks were analyzed separately, using standard procedures in circular statistics. Mean angles for the turtles exposed to the identical color of each light source (or its control treatment) were pooled and then used to determine a second order mean angle and r-vector (dispersion) for that color. Rayleigh tests (Zar 1999) were applied to each distribution to determine whether it showed significant clustering, that is, orientation toward, away or at some other angle relative to the light stimulus. In all statistical tests, the null hypothesis of a uniform distribution of mean angles was rejected when probabilities were $\leq 0.05$.

To determine whether the turtles showed changes in swimming with repeated testing, we compared their dispersion (r-vector) during the first, second, and third exposure to the colored light stimulus.

\section{RESULTS}

A total of 32 juvenile turtles were obtained from 10 nests ( 1 to 5 turtles per nest; Table 1 ) with 16 turtles exposed to lightsticks and 16 to LEDs.

Light stimulus characteristics. The lightsticks (Fig. 2) showed the following properties (of peak spectral energy and irradiance measured at $5 \mathrm{~cm}$ from the source): yellow, $580 \mathrm{~nm}$ at $0.93 \mu \mathrm{W}$; blue, $460 \mathrm{~nm}$ at $0.44 \mu \mathrm{W}$; and green, $520 \mathrm{~nm}$ at $1.84 \mu \mathrm{W}$. For the LEDs (Fig. 2) the data were: orange, $600 \mathrm{~nm}$ at $1.1 \mu \mathrm{W}$; blue, $460 \mathrm{~nm}$ at $4.7 \mu \mathrm{W}$; and green $530 \mathrm{~nm}$ at $6.4 \mu \mathrm{W}$.

Control presentations. The turtles showed no significant orientation during the control presentations of the lightsticks (Fig. 3a) or the LEDs (Fig. 4a). 

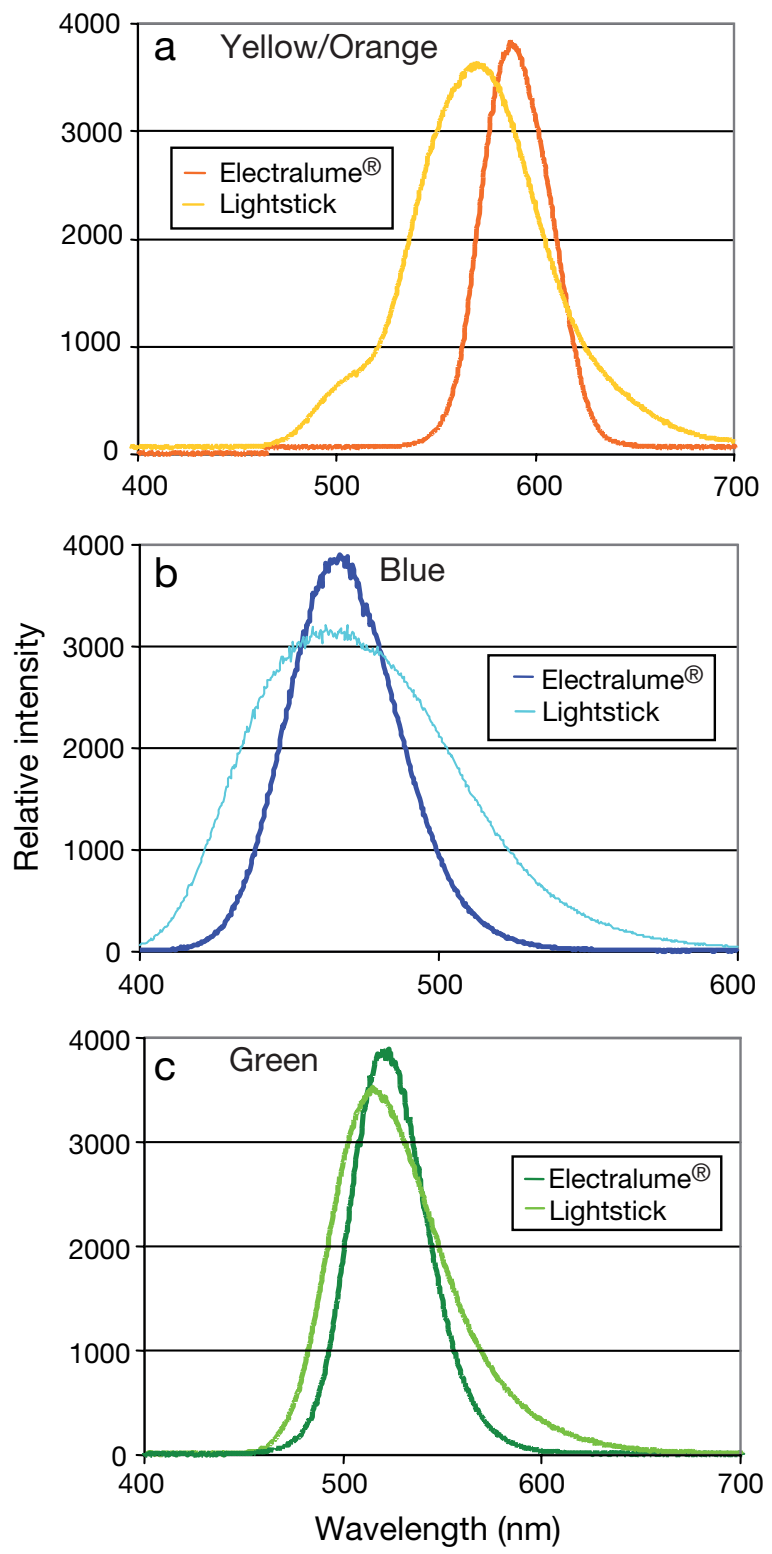

Fig. 2. Spectral energy distributions for the lights. (a) Yellow lightstick and orange LED; (b) blue lightstick and LED; (c) green lightstick and LED

Responses to the lights. The turtles showed no obvious trend in dispersion change over the duration of testing. During the first, second and third exposures to colored lightsticks the r-vectors were $0.86,0.89$, and 0.79 , respectively. For the colored LEDs, they were $0.76,0.80$, and 0.81 .

Turtles exposed to yellow lightsticks oriented significantly away from the light $\left(134^{\circ}\right.$; Rayleigh $\mathrm{p}<0.05$; Fig. 3b) but failed to show significant orientation when presented with blue (Fig. 3c) or green (Fig. 3d) lightsticks. A response to the green lightstick closely approached significance $\left(138^{\circ} ;\right.$ p $<0.10 ;$ Fig. $\left.3 d\right)$.
Table 1. Dermochelys coriacea. Treatment, turtle number, nest source and age at testing for the 32 juvenile leatherbacks used in this study

\begin{tabular}{|c|c|c|}
\hline $\begin{array}{l}\text { Light } \\
\text { treatment and } \\
\text { turtle number }\end{array}$ & $\begin{array}{c}\text { Nest } \\
\text { number }\end{array}$ & $\begin{array}{l}\text { Age }(d) \text { at } \\
\text { testing }\end{array}$ \\
\hline \multicolumn{3}{|l|}{ Lightsticks } \\
\hline 1 & 1 & 5 \\
\hline 2 & 1 & 5 \\
\hline 3 & 1 & 5 \\
\hline 4 & 1 & 5 \\
\hline 5 & 2 & 7 \\
\hline 6 & 2 & 8 \\
\hline 7 & 2 & 8 \\
\hline 8 & 3 & 16 \\
\hline 9 & 3 & 23 \\
\hline 10 & 3 & 23 \\
\hline 11 & 4 & 27 \\
\hline 12 & 5 & 30 \\
\hline 13 & 5 & 31 \\
\hline 14 & 5 & 33 \\
\hline 15 & 6 & 42 \\
\hline 16 & 6 & 42 \\
\hline \multicolumn{3}{|l|}{ LEDs } \\
\hline 17 & 7 & 5 \\
\hline 18 & 7 & 5 \\
\hline 19 & 8 & 9 \\
\hline 20 & 8 & 9 \\
\hline 21 & 8 & 13 \\
\hline 22 & 9 & 13 \\
\hline 23 & 10 & 16 \\
\hline 24 & 10 & 16 \\
\hline 25 & 1 & 22 \\
\hline 26 & 2 & 29 \\
\hline 27 & 2 & 29 \\
\hline 28 & 4 & 35 \\
\hline 29 & 3 & 35 \\
\hline 30 & 3 & 35 \\
\hline 31 & 4 & 36 \\
\hline 32 & 4 & 40 \\
\hline
\end{tabular}

Turtles exposed to green LEDs also oriented significantly away from the light $\left(143^{\circ}, \mathrm{p}<0.05\right.$; Fig. $\left.4 \mathrm{~d}\right)$ but failed to show significant orientation when exposed to orange (Fig. 4b) or blue (Fig. 4c) LEDs.

\section{DISCUSSION}

All of the lights emitted wavelengths within the range of those detected by leatherback hatchlings (360 to $660 \mathrm{~nm}$ ), and all stimulus intensities were at least $1 \log$ unit above threshold (as measured from retinal responses; Horch et al. 2008). We conclude that juvenile leatherbacks between 5 and $42 \mathrm{~d}$ of age are either not attracted to lightsticks and LEDs, or are repelled by them. These results differ from those shown by posthatchling and juvenile ( 2.5 yr old) loggerheads which, when tested under similar circumstances, were attracted to the lights (Lohmann et al. 2006, Wang et al. 2007). 
(a) Control lightstick

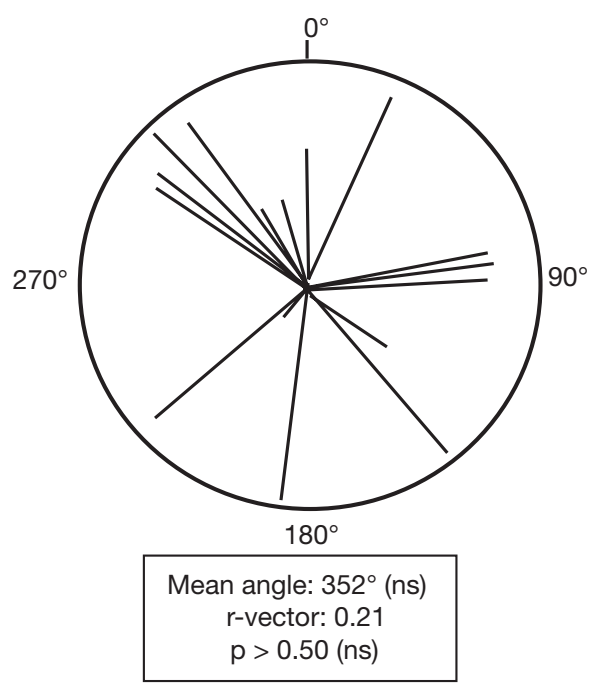

(c) Blue lightstick

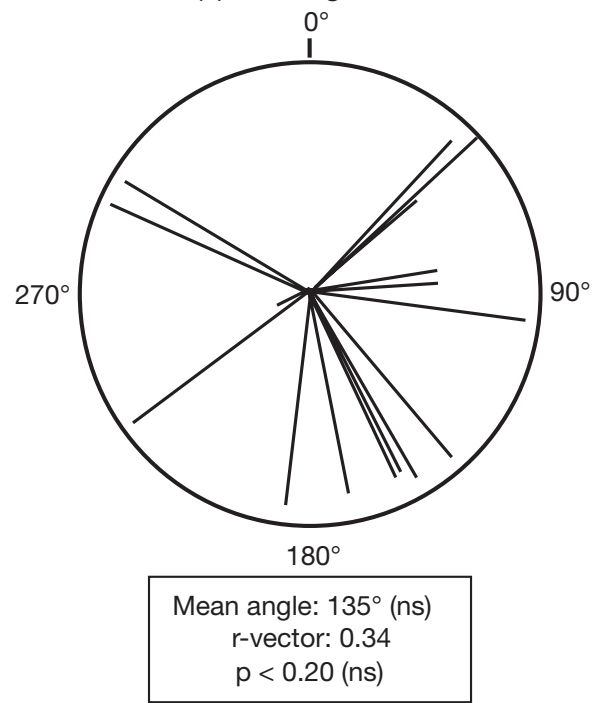

(b) Yellow lightstick

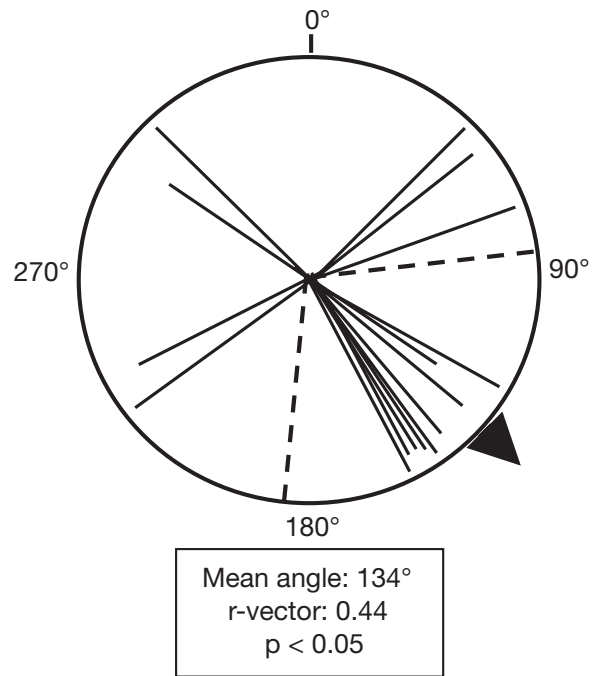

(d) Green lightstick

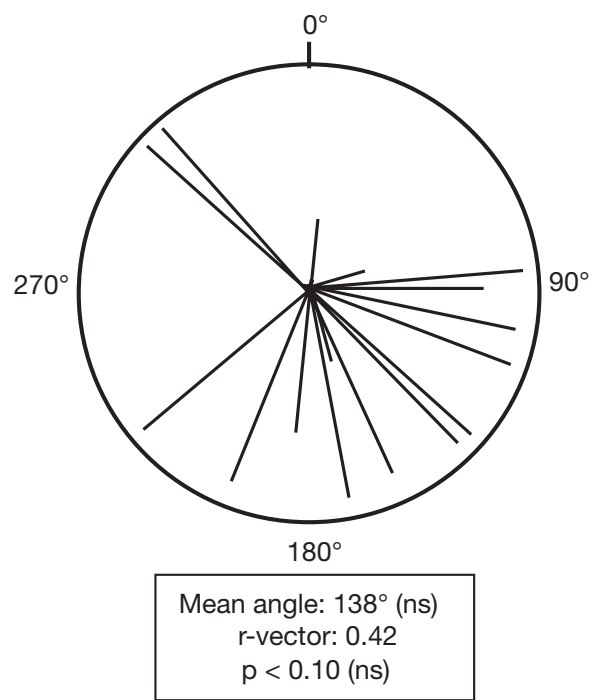

Fig. 3. Dermochelys coriacea. Circle diagrams showing the orientation of 16 turtles when presented with lightsticks: (a) control, (b) yellow, (c) blue, and (d) green. Before trials each evening the lights were rotated $90^{\circ}$ to the right of their position the previous evening; $0^{\circ}$ is toward the light. Solid lines originating in the center represent the mean swimming direction of an individual turtle. Dashed lines in (b) are 95\% confidence intervals for the mean angle. Length of the line corresponds to the $\mathrm{r}$-vector for the respective turtle, with the radius of the circle being $\mathrm{r}=1.0$. Significant orientation is shown only to the yellow lightstick. ns: not significant

\section{Factors affecting marine turtle bycatch on longlines}

Leatherbacks and loggerheads are the marine turtle species most often captured on longlines (Watson et al. 2005). Most leatherbacks are captured by external ('foul') hooking in the 'shoulder', axilla or flipper; however, a few swallow the baits and are hooked internally (Yeung 1999, 2001, Garrison \& Richards 2004, Watson et al. 2005). Leatherbacks may attempt to ingest baits but have difficulty locating the target. Alternatively, they may most often be attracted to the area by cues not associated with the fishing gear and blunder into the lines. The absence of any behavioral observations at sea makes interpretation difficult. Most loggerheads, however, are hooked internally (Yeung 1999, 2001, Garrison \& Richards 2004, Watson et al. 2005) indicating that they typically ingest the baits.

Scientists and fishers are working on ways to reduce bycatch without decreasing capture rates of the target fish species. Changes in gear and in fishing practices 
(a) Control LED

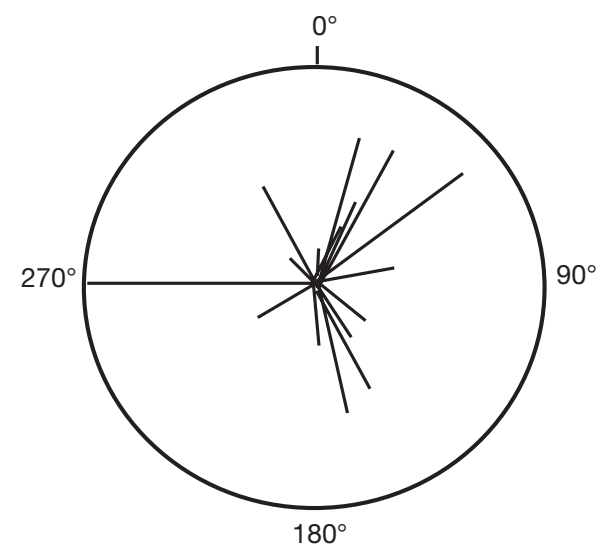

Mean angle: $35^{\circ}$ (ns) r-vector: 0.18 $\mathrm{p}>0.50$ (ns)

(c) Blue LED

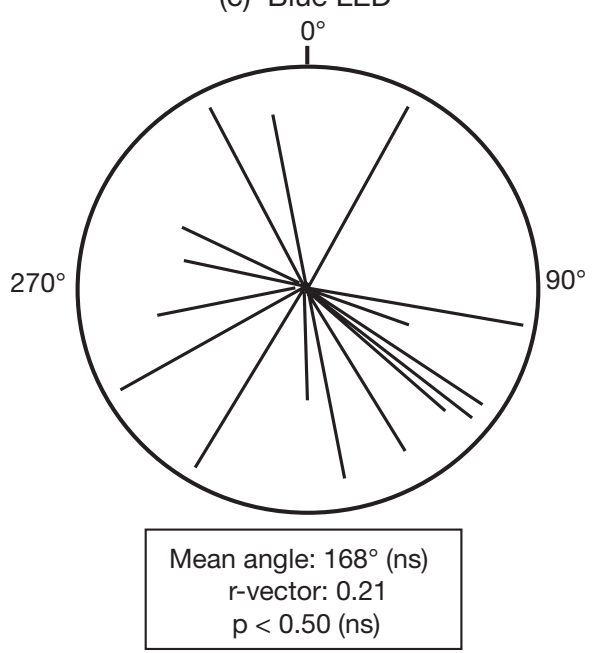

(b) Orange LED

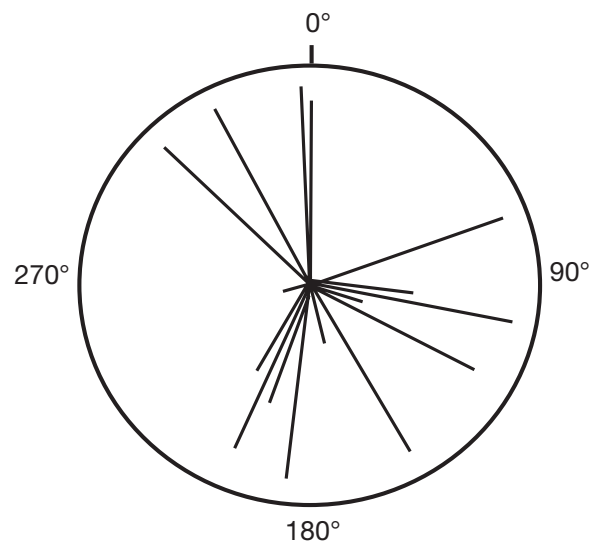

Mean angle: $147^{\circ}$ (ns) r-vector: 0.22 $\mathrm{p}<0.50$ (ns)

(d) Green LED

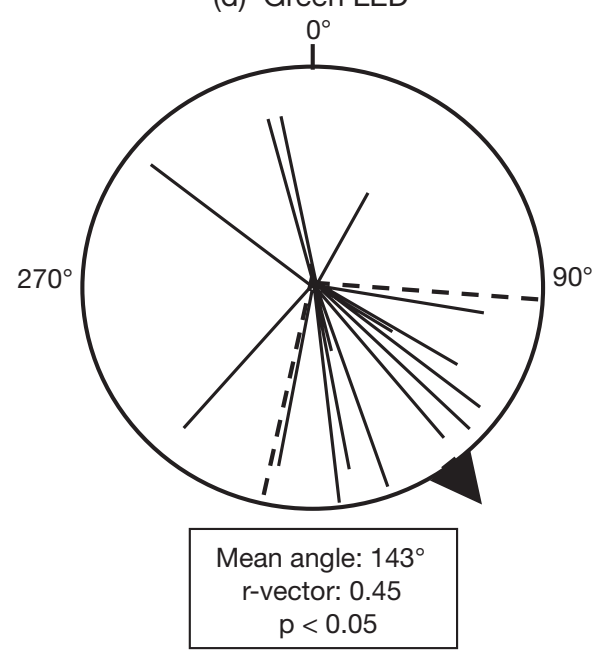

Fig. 4. Dermochelys coriacea. Circle diagrams showing the orientation of a different group of 16 turtles when presented with LEDs: (a) control, (b) orange, (c) blue, and (d) green. Format as in Fig. 3. Significant orientation is shown only to the green LED. ns: not significant

have resulted in significant bycatch reductions for turtles (Bolten et al. 2002, Bolten \& Bjorndal 2003, 2004, 2005, Boggs 2004, Watson et al. 2005). The changes include modification of the hook configuration (use of 'circle' instead of ' $\mathrm{J}$ ' hooks), use of different baits, fishing in cooler waters (Watson et al. 2005) and setting the hooks at depths below those where the turtles are most often found (Polovina et al. 2003, 2004). Changing the duration of the set ('soak time') relative to the light-dark cycle is also effective. Fewer loggerheads are caught when soak time during the day is reduced (Bolten \& Bjorndal 2003, Watson et al. 2005).

Both loggerheads and leatherbacks might be induced to search for food in the vicinity of longlines by bait odors, by visual stimuli from the gear, or by both variables (Swimmer et al. 2005). Experiments with juvenile loggerheads in large enclosures have shown that the turtles are attracted to longline floats and to the shiny snaps used to attach gangions to the mainline (Hataway \& Mitchell 2001). Sea turtles have a well-developed olfactory sense and are capable of discriminating between odors (Manton et al.1972). Juvenile leatherbacks under laboratory conditions show a positive rheotaxis when presented with jellyfish extracts in currents (Constantino \& Salmon 2003), but whether leatherbacks are attracted to the odors of baits (squid or mackerel) that are not part of their diet is unknown.

At sea, the lights suspended on gangions above the baits might also attract the turtles but at the present 
time there is no firm evidence that they do. The problems in interpretation are illustrated in the log book data furnished by the US Atlantic fleet. Witzell (1999) analyzed these data and determined that more leatherbacks and loggerheads were captured when lightsticks were used (primarily at night, but occasionally during the day). However, other differences in fishing gear were unfortunately confounded with lightstick use. That inconsistency made it impossible to attribute the higher bycatch rates of either species only to the lightsticks.

\section{Are leatherbacks attracted to lights?}

Leatherbacks at their northern foraging grounds feed on gelatinous zooplankton at any time of the light-dark cycle but during their migration toward the lower latitudes the turtles feed more often at night (James et al. 2006). Many species of gelatinous zooplankton are bioluminescent and emit light at wavelengths between 440 and $506 \mathrm{~nm}$ (Haddock \& Case 1999). The eyes of hatchling leatherbacks (Horch et al. 2008) and nesting females (Eckert et al. 2006) are especially sensitive to those wavelengths. Davenport (1988) speculated that leatherbacks might find food by orienting toward 'glowing jellies' but that hypothesis has not yet been explored experimentally.

Contrary to the loggerhead studies, the results presented here suggest that juvenile leatherbacks are not attracted by the lights used in the longline fishery and, in some instances, are repelled by them (Figs. 3b \& 4d). In contrast, posthatchling and juvenile loggerheads tested under laboratory conditions are attracted to lightsticks and LEDs regardless of their color (yellow, green, and blue lightsticks; green, violet, and orange LEDs; Lohmann et al. 2006, Wang et al. 2007). Why the 2 species show these differences in response to the lights is unknown.

The 2 species as hatchlings also respond differently to light stimuli. In recent studies (K. A. Fritsches, pers. comm.), loggerheads crawled toward any monochromatic light they could detect, regardless of its intensity, but leatherbacks were either attracted, repelled or indifferent to the same light wavelengths, depending upon stimulus intensity. The intensities of the fishery lights we presented might have by chance induced either indifference or avoidance (Figs. $3 \& 4$ ).

\section{CONCLUSIONS}

Both behavioral (Witherington \& Bjorndal 1991, Lohmann et al. 2006, Wang et al. 2007, K. A. Fritsches pers. comm.) and sensory physiological
(Granda \& O'Shea 1972, Levenson et al. 2004, Eckert et al. 2006, Horch et al. 2008; review: Bartol \& Musick 2003) studies indicate that marine turtles, including loggerheads and leatherbacks, detect the wavelengths emitted by lightsticks and LEDs. However, as emphasized in the previous section, the evidence that fishery lights attract the turtles to longlines is equivocal.

There is a curious disconnection between the results of the laboratory studies carried out on both species and the temporal pattern of turtle captures on longlines. Juvenile loggerheads tested at night in the laboratory were attracted to the lights (Lohmann et al. 2006, Wang et al. 2007) but in the field most loggerheads are captured on longlines during the day when lights are often not used (Bolten et al. 2003, Watson et al. 2004). Juvenile leatherbacks tested at night in the laboratory (present study) either do not orient toward the lights or are repelled by them. Yet in the field, older leatherbacks are captured at night when the lights are commonly used (Watson et al. 2004).

Taken together, these results suggest that the way the turtles respond to the lights under laboratory conditions may not reflect how they respond in the field. The spatial location of the turtles while feeding (Gilman et al. 2007), combined with their temporal rhythms of feeding activity, may play a significant role in their capture rates on longlines. Other possibilities are that the lights may be relatively unimportant in attracting marine turtles, at least when compared to the influence of stimuli from either the longlines or from the area where the lines are set, or that (in the case of leatherbacks) older turtles at sea respond differently to light stimuli than the younger turtles tested in the laboratory.

To clarify the situation, field experiments must be done to specifically determine how the turtles respond to the fishery lights. Should the results be negative, attention can then focus on other possible means of reducing bycatch in the longline fishery. Positive results should be followed by experiments to determine if lights that are shielded (Lohmann et al. 2006), differ in intensity (fishes are more sensitive to light than turtles; Fritsches \& Warrant 2006), in wavelength (turtles are more sensitive to the shorter light wavelengths; Mäthger et al. 2007, Horch et al. 2008) or in flash rate (turtles are less sensitive to faster rates than some pelagic fishes; Eckert et al. 2006, Fritsches \& Warrant 2006) have different effects upon the turtles and the target fishes. Response differences might then be exploited by using lights that are less attractive, unattractive or undetectable (Johnsen 2006) to the turtles but that continue to lure the target fishes to the baits. 
Acknowledgements. This study was a Masters thesis by J.M.G., and was supported by a contract from the Pacific Islands Fisheries Science Center, NOAA Fisheries. We thank W. Irwin for advice on the test tank recording system. We are especially grateful to S. P. Epperly who served on the thesis committee and whose comments on earlier drafts vastly improved the thesis. S. Ceriani and C. Mott spent many hours feeding leatherbacks and keeping them healthy. Without their assistance it would have been difficult to find the time to do these experiments. This project was carried out under State (Florida TP \#173) permit and was approved by the University Institutional and Animal Care Committee.

\section{LITERATURE CITED}

Bartol SM, Musick JA (2003) Sensory biology of sea turtles. In: Lutz PL, Musick JA, Wyneken J (eds), The biology of sea turtles, Vol II. CRC Press, Boca Raton, FL, p 79-102

Boggs CH (2004) Hawaii fishing experience to reduce pelagic longline bycatch of sea turtles. In: Long KJ, Schroeder BA (eds), Proceedings of the International Technical Expert Workshop on Marine Turtle Bycatch in Longline Fisheries. US Dept Commerce NOAA Tech Memo NMFS-F/OPR-26, p 121-138

Bolten A, Bjorndal K (2003) Experiment to evaluate gear modification on rates of sea turtle bycatch in the swordfish longline fishery in the Azores - Phase 2. Final project report submitted to the US NMFS. Archie Carr Center for Sea Turtle Research University of Florida, Gainesville, FL

Bolten A, Bjorndal K (2004) Experiment to evaluate gear modification on rates of sea turtle bycatch in the swordfish longline fishery in the Azores - Phase 3. Final project report submitted to the US NMFS. Archie Carr Center for Sea Turtle Research, University of Florida, Gainesville, FL

Bolten A, Bjorndal K (2005) Experiment to evaluate gear modification on rates of sea turtle bycatch in the swordfish longline fishery in the Azores - Phase 4. Final project report submitted to the US NMFS. Archie Carr Center for Sea Turtle Research, University of Florida, Gainesville, FL

Bolten A, Martins H, Isidro E, Ferreira R, and others (2002) Preliminary results of experiments to evaluate effects of hook type on sea turtle bycatch in the swordfish longline fishery in the Azores. Report to the SEFSC NMFS, Contract numbers NA96FE0393 and NA16FM1378, p 1-9

Bugoni L, Krause L, Petry MV (2001) Marine debris and human impacts on sea turtles in southern Brazil. Mar Pollut Bull 42:1330-1334

Chan E, Liew H (1996) Decline of the leatherback population in Terengganu, Malaysia 1956-1995. Chelonian Conserv Biol 2:196-203

Constantino MA, Salmon M (2003) Role of chemical and visual cues in food recognition by leatherback posthatchlings (Dermochelys coriacea L). Zoology 106:173-181

Davenport J (1988) Do diving leatherbacks pursue glowing jelly? Br Herpetol Soc Bull 24:20-21

Eckert SA, Levenson D, Crognale M (2006) The sensory biology of sea turtles: What can they see and how can this help them avoid fishing gear? In: Swimmer Y, Brill RW (compilers and eds) Sea turtle and pelagic fish sensory biology: developing techniques to reduce sea turtle bycatch in longline fisheries. NOAA Tech Memo NMFS-PIFSC-7, p 8-16

Fritsches KA, Warrant EJ (2006) Differences in the visual capabilities of sea turtles and blue water fishes: implications for bycatch reduction. In: Swimmer Y, Brill RW (compilers and eds) Sea turtle and pelagic fish sensory biology: developing techniques to reduce sea turtle bycatch in longline fisheries. NOAA Tech Memo NMFS-PIFSC-7, p 1-7

Garrison LP, Richards PM (2004) Estimated bycatch of marine mammals and turtles in the U.S. Atlantic pelagic longline fleet during 2003. NOAA Tech Memo NMFS-SEFSC-527, p 1-57

Gilman E, Kobayashi D, Swenarton T, Brothers N, Dalzell P, Kinan-Kelly I (2007) Reducing sea turtle interactions in the Hawaii-based longline swordfish fishery. Biol Conserv 139:19-28

- Granda AM, O'Shea PJ (1972) Spectral sensitivity of the green turtle (Chelonia mydas mydas) determined by electrical responses to heterochromatic light. Brain Behav Evol 5:143-154

> Haddock SHD, Case JF (1999) Bioluminescence spectra of shallow and deep-sea gelatinous zooplankton: ctenophores, medusae and siphonophores. Mar Biol 133: $571-582$

Hataway D, Mitchell J (2001) Report on gear evaluations to mitigate sea turtle capture and mortality on pelagic longlines using captive reared sea turtles. NMFS/SEFSC Pascagoula, MS, p 1-19

Horch K, Gocke J, Salmon M, Forward R (2008) Visual spectral sensitivity of hatchling loggerhead (Caretta caretta L) and leatherback (Dermochelys coriacea L) sea turtles, as determined by single-flash electroretinography. Mar Freshw Behav Physiol (in press)

Hoyle M (1994) Continuing sea turtle exploitation in Antigua and Barbuda, West Indies. Mar Turtle Newsl 64:21-22

IUCN (International Union for the Conservation of Nature and Natural Resources, The World Conservation Union) (1994) Caretta caretta. 2007 IUCN Red List of Threatened Species. IUCN, Gland. Available at: www.iucnredlist.org/ search/details.php/3897/all. Accessed December 2007

> James MC, Ottensmeyer CA, Eckert SA, Myers RA (2006) Changes in diel diving patterns accompany shifts between northern foraging and southward migration in leatherback turtles. Can J Zool 84:754-765

Johnsen S (2006) Mathematical model of the visual abilities of sea turtles and pelagic fishes. In: Swimmer Y, Brill RW (compilers and eds) Sea turtle and pelagic fish sensory biology: developing techniques to reduce sea turtle bycatch in longline fisheries. NOAA Tech Memo NMFSPIFSC-7, p 18-23

Jones TT, Salmon M, Wyneken J, Johnson C (2000) Rearing leatherback hatchlings: protocols, growth and survival. Mar Turtle Newsl 90:3-6

Kamezaki N, Matsuzawa K, Abe O, Asakawa H, Fujii T, Goto K (2003) Loggerhead turtles nesting in Japan. In: Bolten $A B$, Witherington BE (eds) Loggerhead sea turtles. Smithsonian Institution Press, Washington, DC, p 210-217

Levenson DH, Eckert SA, Crognale MA, Deegan JFI, Jacobs GH (2004) Photopic spectral sensitivity of green and loggerhead sea turtles. Copeia 2004:908-914

> Lewison RL, Crowder LB (2007) Putting longline bycatch of sea turtles into perspective. Conserv Biol 21:79-86

Lewison RL, Freeman SA, Crowder LB (2004a) Quantifying the effects of fisheries on threatened species: the impact of pelagic longlines on loggerhead and leatherback sea turtles. Ecol Lett 7:221-231

Lewison RL, Crowder LB, Read AJ, Freeman SA (2004b) Understanding impacts of fisheries bycatch on marine megafauna. Trends Ecol Evol 19:598-604

Limpus C, Limpus DJ (2003) The loggerhead turtle Caretta caretta in the Equatorial and Southern Pacific Ocean: a species in decline. In: Bolten $\mathrm{AB}$, Witherington $\mathrm{BE}$ (eds) 
Loggerhead sea turtles. Smithsonian Institution Press, Washington, DC, p 199-209

Lohmann KJ, Wang JH, Boles LC, McAlister J, Higgins B, Lohmann CMF (2006) Development of turtle-safe light sticks for use in longline fisheries. In: Swimmer Y, Brill RW (compilers and eds) Sea turtle and pelagic fish sensory biology: developing techniques to reduce sea turtle bycatch in longline fisheries. NOAA Tech Memo NMFSPIFSC-7, p 65-76

Lutcavage ME, Plotkin P, Witherington BE, Lutz PL (1997) Human impacts on sea turtle survival. In: Lutz P, Musick J (eds) The biology of sea turtles. CRC Press, Boca Raton, FL, p 387-409

Manton ML, Carr A, Ehrenfeld DW (1972) Chemoreception in the migratory sea turtle Chelonia mydas. Biol Bull 143: 184-195

Marcovaldi MA, Chaloupka M (2007) Conservation status of the loggerhead sea turtle in Brazil: an encouraging outlook. Endang Species Res 3:133-143

Mäthger LM, Litherland L, Fritsches KA (2007) An anatomical study of the visual capabilities of the green turtle, Chelonia mydas. Copeia 2007:169-179

Meylan AB, Witherington BE, Brost B, Rivero R, Kubilis PS (2006) Sea turtle nesting in Florida, USA: assessments of abundance and trends for regionally significant populations of Caretta, Chelonia and Dermochelys. In: Frick M, Panagopoulou A, Rees AF, Williams K (compilers) Book of abstracts. 26th Annual Symposium on Sea Turtle Biology and Conservation. International Sea Turtle Society, Athens, GA, p 306

NMFS and USFWS (National Marine Fisheries Service and US Fish and Wildlife Service) (2007) Loggerhead sea turtle (Caretta caretta) 5 year review: summary and evaluation. Jacksonville Ecological Services Field Office, Jacksonville, FL, p 1-67

Parris LP, Lamont MM, Carthy RR (2002) Increased incidence of red imported fire ant (Hymenoptera: Formicidae) presence in loggerhead sea turtle (Testudines: Cheloniidae) nests and observations of hatchling mortality. Fla Entomol 85:514-517

Polovina J, Howell E, Parker D, Balazs G (2003) Dive-depth distribution of loggerhead (Caretta caretta) and olive ridley (Lepidochelys olivacea) sea turtles in the central North Pacific: might deep longline sets catch fewer turtles? Fish Bull (Wash DC) 101:189-193

Polovina J, Balazs G, Howell E, Parker D, Seki M, Dutton P (2004) Forage and migration habitat of loggerhead (Caretta caretta) and olive ridley (Lepidochelys olivacea) sea turtles in the central North Pacific Ocean. Fish Oceanogr 13:36-51

Spoczynska JOI (1970) Rearing hatchlings of Dermochelys coriacea. Br J Herpetol 4:189-191

Spotila JR, Reina RR, Steyermark AC, Plotkin PT, Paladino FV (2000) Pacific leatherback turtles face extinction. Nature 405:529-530

Southwood A, Higgins B, Brill R, Swimmer Y (2006) Chemoreception in loggerhead sea turtles: an assessment of the feasibility of using chemical deterrents to prevent sea turtle interactions with longline fishing gear. In: Swimmer
Y, Brill RW, (compilers and eds) Sea turtle and pelagic fish sensory biology: developing techniques to reduce sea turtle bycatch in longline fisheries. NOAA Tech Memo NMFS-PIFSC-7, p 41-56

Stewart KR (2007) Establishment and growth of a sea turtle rookery: the population biology of the leatherback in Florida. PhD dissertation, Duke University, Durham, NC

Sutanto-Suwelo I, Yunia-Yusuf C, Yamasaki K (1994) Leatherback turtles at Jamursba-Medi Beach, Kepala, Burung Irian Jaya. Mar Turtle Newsl 64:12

Swimmer Y, Arauz R, Higgins B, McNaughton L, McCraken M, Ballestro J, Brill R (2005) Food color and marine turtle feeding behavior: Can blue bait reduce turtle bycatch in commercial fisheries? Mar Ecol Prog Ser 295:273-278

Swimmer Y, Brill R (2006) Sea turtle and pelagic fish sensory biology: developing techniques to reduce sea turtle bycatch in longline fisheries. US Dep Commer NOAA Tech Memo NOAA-TM-NMFS-PIFSC-7

Swimmer Y, McNaughton L, Southwood A, Brill R (2006) Tests of repellent bait to reduce turtle bycatch in commercial fisheries. In: Swimmer Y, Brill RW (compilers and eds) Sea turtle and pelagic fish sensory biology: developing techniques to reduce sea turtle bycatch in longline fisheries. NOAA Tech Memo NMFS-PIFSC-7, p 57-64

Troëng S, Harrison E, Evans D, de Haro A, Vargas E (2007) Leatherback turtle nesting trends and threats at Tortuguero, Costa Rica. Chelonian Conserv Biol 6:117-122

TEWG (Turtle Expert Working Group) (2007) An assessment of the leatherback turtle population in the Atlantic Ocean. NOAA Tech Memo NMFS-SEFSC-555, p 1-116

> Wang JH, Boles LH, Higgins B, Lohmann KJ (2007) Behavioral responses of sea turtles to lightsticks used in longline fisheries. Anim Conserv 10:176-182

Watson J, Foster D, Epperly SP, Shah A (2004) Experiments in the Western Atlantic Northeast Distant Waters to evaluate sea turtle mitigation measures in the pelagic longline fishery. Report on experiments conducted in 2001-2003. US NMFS Pascagoula, MS

- Watson JW, Epperly SP, Shah A, Daniel GF (2005) Fishing methods to reduce sea turtle mortality associated with pelagic longlines. Can J Fish Aquat Sci 62:965-981

Witherington BE, Bjorndal K (1991) Influences of wavelength and intensity on hatchling sea turtle phototaxis: implications for sea-finding behavior. Copeia 1991:1060-1069

Witham R (1977) Dermochelys coriacea in captivity. Mar Turtle Newsl 3:6-7

Witzell WN (1999) Distribution and relative abundance of sea turtles caught incidentally by the U.S. pelagic longline fleet in the western North Atlantic Ocean 1992-1995. Fish Bull (Wash DC) 97:200-211

Yeung C (1999) Estimates of marine mammal and marine turtle bycatch by the U.S. Atlantic pelagic longline fleet in 1998. NOAA Tech Memo NMFS-SEFSC-430

Yeung C (2001) Estimates of marine mammal and marine turtle bycatch by the U.S. Atlantic pelagic longline fleet in 1999-2000. NOAA Tech Memo NMFS-SEFSC-467

Zar JH (1999) Biostatistical analysis. Prentice Hall, Englewood Cliffs, NJ

Submitted: November 8, 2007; Accepted: January 22, 2008 Proofs received from author(s): March 1, 2008
Editorial responsibility: Rebecca Lewison,

San Diego, California, USA 